\title{
ASYNCHRONOUS DISCUSSION GROUPS IN TEACHER TRAINING CLASSES: PERCEPTIONS OF NATIVE AND NON-NATIVE STUDENTS
}

\author{
Sigrun Biesenbach-Lucas \\ Assistant Professor, Department of Language and Foreign Studies \\ American University \\ 4400 Massachusetts Avenue, N.W., Washington, DC 20016 \\ Telephone: (202) 885-2247 \\ Fax: (202) 885-1356 \\ Email: sblucas@american.edu
}

\begin{abstract}
This paper discusses students' perceptions of an asynchronous electronic discussion assignment implemented shortly after the technology had been introduced to the university. In addition to the weekly face-to-face class meetings, students in two graduate level teacher training courses were assigned to small groups for an entire semester and made weekly contributions to their group's course web discussion forum in which they discussed course content. Students were to make explicit references to course readings and postings by their group members. The instructor evaluated students' postings on a weekly basis. At the end of the course, students completed a survey assessing their satisfaction and asking for their suggestions for modification of the particular assignment type and format. For all students, the extension of course-related discussions outside the regular face-to-face class meetings offered benefits in the form of greater social interaction with other class members; for the non-native speakers among the students, the asynchronous discussions facilitated assimilation of course content, but it was not perceived as providing additional language practice. For all students, the two main issues perceived as negative related to their perceptions of forced, unnatural interaction promoted by the asynchronous discussions and lack of topic prompts, the requirement to make connections to prior postings, and the frequency of required contributions to discussions. Possible reasons for students' perceptions are explored and suggestions for further research are provided.
\end{abstract}

\section{KEYWORDS}

Technology, learning effectiveness, access, discussion boards, asynchronous discussion groups, computer-mediated communication, student perceptions, non-native speakers

\section{INTRODUCTION}

An increasing number of university courses are adding greater flexibility to the traditional lecture format, class discussions, and typical evaluation types (mid-terms, finals, final papers) with the aid of new, technology-supported media. It is assumed, often based on sociocognitive and constructivist theories of learning, that "much learning goes on outside the formal classroom" [1], often in collaboration with fellow students and in reflective contemplation of course material [2]. The pedagogical merits of certain computer-mediated technology as well as its suitability to extend collaborative deliberation of course materials outside the classroom are becoming more widely acknowledged $[3,4,5]$. 
Computer technologies which facilitate collaboration among students as well as teachers and students have in fact received a lot of scrutiny [cf. 6, 7, 8]. Many courses make use of asynchronous technology, such as listservs, electronic mail, and discussion boards/forums [2, 9, 10, 11, 12, 13, 14]. Most use of asynchronous technology "has been instituted with little or no consideration of the impact on student learning" [15, cf. also 8], and little research has critically examined the use of this technology within specific implementation formats. Also, research on asynchronous computer-mediated interaction has concentrated on university content courses in which the participants were native speakers of English, but relatively little research has examined use of asynchronous technology in graduate level courses attended by both native and non-native speakers of English to support students' learning. Kahmi-Stein found that participation of non-native students was enhanced in asynchronous web discussions in her comparison of computer-mediated and face-to-face learning environments [12]. Due to differences in time, asynchronous exchanges naturally proceed at a slow pace, consequently allowing for more planning and reading time. Thus, they may be particularly suitable as an extension of class discussions in academic courses in which non-native speakers of English are enrolled. These students tend to lack not only linguistic flexibility to participate in American higher education courses, but they are also not used to a critical engagement with course content as is expected particularly in graduate level classes. Asynchronous discussions have been found to promote such development of critical thinking [7, 16, 17, $18,19,20]$ reflected in "a higher level of scholarly discourse than is typical in many [face-to-face] classes" [14]. Joy and Garcia claim that "learning effectiveness is a function of effective pedagogical practices" and urge that research should focus on "what combination of instructional strategies and delivery media will best produce the desired learning outcome for the intended audience" [8].

This project represents a case study of asynchronous discussions implemented in graduate level teacher training courses, in which both native and non-native students were enrolled. The goal was to bring together students from different cultures and languages and provide them with an opportunity for courserelated interaction outside the classroom through a medium that had recently been introduced to the university community. The paper discusses the implementation parameters of the project and examines students' reactions to the asynchronous interaction, focusing specifically on similarities and differences in native and non-native students' attitudes toward the discussion board component, which was used to supplement regular face-to-face class meetings. It is hoped that the experiences and insights developed in this project may provide an alternative format for instructors who have opportunities to introduce asynchronous technology into their classrooms, perhaps as a result of facilitative course management software, but also to increase an awareness of the various parameters that affect the feasibility and success of such technology-supported activities.

\section{REVIEW OF LITERATURE}

To date, numerous studies have reported on applications of computer technology in higher education to support the teaching-learning process. Research on the use of asynchronous technologies in general has found that they enhance learning for students in that they provide structured opportunities for students to engage with course material [3, 21, 22, 23, 24, 25, 26, 27, 28]. Longitudinal asynchronous interaction among students has been found to be preferable to "one-shot [synchronous] CMC groups" [27] in that it allows participants to develop a better affective climate in which learning can occur. Similarly, "asynchronicity changes the dynamics of relationships" [29] as participants have more time to reflect on and produce their contributions. Benefits of asynchronous discussions also include opportunities to think about course content and to address a diverse set of topics in more depth than can be done in class or in a synchronous environment, thus allowing students to conceptualize a topic from multiple viewpoints and to contribute to each other's understanding [16, 28, 30, 31,32]. Learners actively construct their own learning by engaging themselves and others in reflective explorations of ideas, drawing conclusions based 
on their explorations and synthesizing those conclusions with previous knowledge in what is most often a non-linear process [32]. In this process of learning, students are engaged in more inductive, problem solving activities as opposed to deductive, analytic teacher-based exercises and lectures [33], and instructors may prompt students' engagement by providing open-ended questions and problems that require discussion and collaborative work to answer/solve [34].

Computer-mediated technology also provides tools that are useful in promoting collaborative learning activities [1, 7, 35, 36] that can "mediate communication between learners" [37]. Traditional classroom interaction places the teacher at the center of all activities as transmitter of knowledge and orchestrator of student interaction. Even if students engage in collaborative small group tasks, the teacher is usually around and monitors students' progress while providing input on how to solve a particular task-a condition which may hinder "reflection and facilitative interaction" [13]. Asynchronous discussions allow students, in groups, to collaborate with each other in an exchange of opinions, experiences, and interpretations of course content [37, 38]. This enables them to become "problem-solvers rather than just memorizers of facts" [10]. Through exposure to group members' perspectives and through joint evaluation of topics, students can arrive at a more complete understanding of course content than they might through teacher presentations and delivery only [3, 20,39]. Bannon points out that such computermediated collaboration "allows for the cross-fertilisation of ideas, [and] for the fostering of multidisciplinary perspectives on related problems" [1]. In a review of numerous studies on collaborative learning, Johnson and Johnson [30] concluded that collaborative tasks lead to greater student satisfaction with learning processes and outcomes. As a result, principles of cooperation and collaboration may be effectively realized in such technology-supported interaction among students $[22,35]$.

In addition, research indicates that asynchronous discussions have been evaluated positively by nonnative students, who cite social interaction as a major benefit of discussion board postings [28]. Asynchronous technology is also a useful medium for promoting development of English language skills for non-native speaking students [13] and for increasing participation among this group of students [12]. Non-native students often do not participate much in face-to-face class situations because they lack linguistic flexibility to make contributions quickly, but also because they are not used to the more active role that students in an American education environment are expected to play [33]. Research, such as that by Kahmi-Stein [12] is promising as it indicates that asynchronous discussions may be a medium for nonnative students to overcome their linguistic limitations and to develop critical thinking abilities they are not used to expressing.

However, some studies have also concluded that having students discuss course issues after class through an asynchronous medium is not sufficient for increasing their critical thinking skills and for influencing classroom group dynamics, perhaps due to infrequency of and time lags between postings that an asynchronous medium entails [23, 40]. MacKinlay argues that the success of asynchronous technology in education depends on how the technology is integrated into the curriculum and the course work. She reasons, "if there is no learning framework in place then learner uncertainty may affect participation and motivation levels" [25]. Similarly, other researchers [16,41] caution that such technology needs to be integrated carefully with other learning activities, and that instructors need to provide structure to the electronic discussion activity, particularly when electronic discussions are new to students and used in addition to other classroom activities. Chong, while identifying a number of advantages of electronic conferencing technology for students, including promotion of active, reflective engagement with course materials, and social relationships [cf. also 16], also points out that electronic discussions can be seen by students as burdensome busywork and can fail to prompt meaningful communication [4]. Similarly, Stepp-Greany [42] found that the university students she surveyed had more neutral than positive attitudes toward discussion board activities, and slightly more than half her students indicated that they would 
prefer a traditional, non-technology supported class.

Scarce's study also provides a candid account of the implementation of longitudinal asynchronous electronic discussion groups with native speakers, from the point of view of the instructor as well as the students [18]. While he acknowledges the benefits of students' collaboration particularly in terms of developing critical thinking skills, he also discusses potential areas in which such technology-supported activities can be improved. He suggests that reading of previous group members messages can be assured by requiring students to respond to other members' messages and making part of the students' grade on the assignment contingent upon explicit responses [14] [43]. Scarce also recommends that students be encouraged to post more than once a week in order to make the interaction less "a series of essays" and more "discussion-like" [18].

Many studies, as pointed out above, have reported on positive effects of asynchronous discussions, but they have largely adopted the perspective of the course instructor, who evaluates the quality of students' contributions to electronic discussions. Fewer studies have focused on the perspective of the students, and even fewer have explicitly compared native and non-native students' attitudes to asynchronous discussions. Studies need to examine if claims that asynchronous discussions "[allow] everyone to be heard" [43], that social relationships are built, and that course material is better understood and more critically received if courses have asynchronous discussion components, are as valid for non-native students enrolled in American university courses as they are for native speakers, and if students' perceptions mirror those of their instructors. Thus, this study builds on those by Kahmi-Stein [12], Chong [4] and Stepp-Greany [41] as it seeks to examine how a particular format of regular asynchronous information exchange among students can influence intercultural attitudes as well as learning of course material among native and non-native students enrolled in the same class [cf. also 45].

\section{DESIGN AND IMPLEMENTATION OF DISCUSSION BOARD ASSIGNMENT}

This project was conducted as a case study following the introduction of BlackBoard course management software at a large university and encouragement from the administration to faculty to "put all courses on the web." Little concrete support was provided to faculty, least of which related to how BlackBoard's discussion board feature could best be integrated as an additional, online component into the various courses offered in each department. In the present study, asynchronous discussions were added as a new, and additional, component to two graduate level teacher training classes, which met face-to-face once a week for two and a half hours of regular class time.

An assignment was designed that required students to make regular contributions to the course web site discussion board supported by BlackBoard. The following goals guided the design of the assignment in the present study: fostering collaboration and thus enhancing understanding of course material; contributing to a critical understanding of course material achieved individually as well as collectively; providing a forum where mutual support and social cohesion could develop; and giving non-native speakers in the class an opportunity to use language and participate outside of class. Thus, it was hoped that electronic discussions would be able to "empower the students and to encourage them to take on the role of critic and inquirer" [18].

At the beginning of the semester, students (22\% non-native speakers from largely Asian backgrounds) in two TESOL teacher training courses (Methodology and Second Language Acquisition-SLA) were randomly assigned to groups of 3 or 4 students by the course instructor, who taught both courses [22, 46, 
47]. This was considered an adequate group size as the groups would be "small enough to avoid free riding while maintaining sufficient numbers to ensure a critical mass for active discussion" [46]. In addition, the small group size would not lead to a message build-up as is typical of discussion board forums in which postings are open to all class members and accumulating messages add to the weekly reading workload of students [47].

In the Methodology class, 17 students were assigned to five groups ( 3 groups of 3 students, and 2 groups of 4 students). Two of the groups (one group of three and one group of four) contained only non-native speakers; the other three groups contained only native speakers. In the SLA class, 19 students were assigned to six groups (4 groups of 3 students, 2 groups of 4 students). One student in a group of three had to drop the course after nearly half the semester, so the remaining two students continued their discussions as a pair for the remainder of the semester. This class had only one non-native speaker, who was part of a group of three. One methodological limitation is, of course, that there was no control over which students were enrolled in which courses, and also how many non-native speakers were enrolled during the time of the study [cf. 40]. Also, while 36 students in two classes may be a relatively small sample, it is similar to the sample size in other studies on asynchronous interaction [cf. 48, and 22, whose studies included 23 and 24 students, respectively] and allows for qualitative analysis [46, 49].

Throughout the semester, the groups remained unchanged, and within their groups, students were required to make weekly contributions to their group's discussion board forum (set up for them by the instructor through BlackBoard) throughout the duration of the courses (one semester) [cf. 22]. It was expected that since students met face-to face only once a week and were not likely to see each other in between classes due to different work and study schedules, they would welcome a forum which allowed them to interact outside the classroom. Unlike other discussion board forums, where students make sporadic postings to be read by all other participants in the course, the goal of the particular arrangement in the present study was to give students an opportunity to engage more deeply with course material and to develop closer ties with group members by learning more about each other in more frequent contributions [cf. 18]. It was expected that a group that stayed together to develop and discuss topics over an extended length of time would have a better opportunity to deepen their understanding of given topics and develop social relationships [cf. 16, 47]. It is more difficult to develop such a sense of community and understanding of course content if postings are sporadic, on varying topics, and made by numerous different students in the class $[50,51]$.

The assignment required students' postings to their group discussion forum to meet specific requirements as described in a set of guidelines and an evaluation form which were distributed to students at the beginning of the semester (see Appendix A). MacKinlay suggests "having 'rules of engagement' [sic.] help to set the scene for online learners especially if this is their first experience of online learning" [25, cf. also 14], as was the case with half the learners in the present study - the other students had used BlackBoard's discussion board feature in the previous semester in another class to respond to prompts provided by that instructor. Students were given rules as to "the minimum number of emails to be sent during one week and/or what constitutes an acceptable [contribution]" [25]. Graham, Scarborough, and Goodwin similarly advise that "guidelines and expectations for participation" as well as "individual and group responsibilities need to be clearly stated" [46].

The requirements for the assignment in the present study were the following: (1) students had to post to the web board within their group at least once a week (but could post more frequently if they so desired), so lurking and non-contribution would not be an issue [cf. 22, 46, 48]; (2) the messages needed to address course related matters, but the specific topics could be selected by the students and their groups - this would prevent the high amount of "unproductive social interaction" found in asynchronous discussion 
[22]; (3) the messages needed to discuss and reflect critically on course content; and (4) students had to respond explicitly to previous contributions by other students in their group [cf. 14, 44, 52] for similar requirements). In this way, it was expected that topics would be discussed in more depth as each subsequent posting would have to build on the previous ones both linguistically and semantically instead of putting forth an independent agenda and topic [43]. In addition, this requirement was expected to counter the effects of random postings, which tend to encourage less collaboration [46]. These electronic group discussions were sustained over 12 consecutive weeks in one semester. The rationale for the assignment as well as posting procedures through the course management software were explained orally in class and a back-up procedure of using regular email for sending messages to group members was discussed at the outset of the courses [cf. 22].

The instructor for both courses was the same. Each week, the instructor evaluated each student's message based on the above criteria; thus, students received weekly feedback on their discussion board contributions $[14,53]$. For the non-native speaker students in the courses, grammatical accuracy was not considered in the evaluation. The criteria were discussed with students during the first week of the semester.

After the instructor had randomly assigned students to groups, students were encouraged to make their postings. It was left up to the students to determine who would begin the weekly thread as well as which topic the group wanted to discuss. In order to minimize the effects of instructor interference and presence [53], and in an effort to foreground the students' role in the discussions, the instructor neither assigned turns for postings, nor made postings to any group's ongoing discussion [cf. in contrast 14, 52]. Over the course of each week in the semester, the instructor kept track of the messages posted to each group forum. The messages were printed out in the order in which they were posted in order to capture the chronological sequence of these ongoing exchanges and to be able to check for connections to previous messages. At the end of each weekly cycle, each group's messages were read and evaluated by the instructor, and an evaluation form was given to each student during the next class session. Typically, the instructor would include brief comments on the content of students' contributions or remind students to follow the guidelines by reflecting critically or referring to their group members' previous messages these tended to be the most frequent "deviations" from the assignment requirements.

At the end of the semester, students completed an anonymous survey (see Appendix B) targeting their perceptions of the social and academic benefits of the assignment through Likert-type items; that is students were asked to rate whether or not and to what degree they felt the discussion board activity allowed them to build relationships with their classmates, deepen their understanding of course content, and enhance their writing skills. The survey also posed open-ended questions asking students to comment on constraints and weaknesses of the task, technical problems, students' experience with similar assignments, as well as providing suggestions for modifying the assignment [cf. 14, 22, 48, 54] for use of similar surveys). The survey was completed during the last face-to-face class meeting; thus all students' survey responses could be tabulated. One limitation of course is that the surveys were self-reported, and not all students may have responded truthfully. In addition, a very small number of students did not respond to all survey questions. This was counteracted by not requiring students to reveal their identities other than whether or not they were native or non-native speakers of English. Factors that may have influenced student perceptions of the discussion board task, such as students' performance on other course tasks, expected course grade, and personality type, were not considered. For each item on the survey, students' responses were averaged for native and non-native students to determine if their attitudes varied for this comparatively new course activity. Tabulated and averaged survey results are referred to throughout the discussion below, and student comments and responses to the open-ended questions are added for illustration when appropriate. 


\section{RESULTS OF STUDENT SURVEY}

Overall, the outcome of the relatively novel discussion board activity was perceived with mixed reactions by students in both the Methodology and the SLA classes. While students responded positively to perceived social and academic benefits of engaging in electronic discussion groups, they had more critical attitudes toward specific parameters of the assignment. Some differences between native and non-native students were noted.

\section{A. Students' Perceptions of Social Benefits of Discussion Groups}

Social benefits were uniformly perceived by all groups in both classes [cf. 16, 18, 47], and especially by the non-native students [cf. 12], as the averages of the tabulated results shown in Table 1 indicate. Comments from both native and non-native students confirmed that the assignment helped build social relationships with their fellow group members and increase multi-cultural awareness [cf. 10]. The averages for native speakers indicate that they ranked the experience as slightly less positive than the nonnative speakers, but this is likely because most of the groups in both classes consisted of native speakers only, thus preventing much multicultural exposure. However, students generally indicated that they enjoyed learning more about their classmates and their experiences and found that the greatest benefit of the discussions was "sharing ideas," "seeing [a] variety of experiences," and "getting to know other students".

Table 1. Survey Results on Social Benefits of Discussion Board Postings: Averages for Native and Non-Native Students in the Two Classes.

\begin{tabular}{|l|c|c|c|c|}
\hline Did the electronic discussion help you ... & \multicolumn{2}{|c|}{ Methodology Class } & \multicolumn{2}{|c|}{$\begin{array}{c}\text { Second Language } \\
\text { Acquisition Class }\end{array}$} \\
\cline { 2 - 5 } Very much 1-2-3-4-5 Not at all & $\begin{array}{c}\text { Native } \\
\text { Speakers }\end{array}$ & $\begin{array}{c}\text { Non-Native } \\
\text { Speakers }\end{array}$ & $\begin{array}{c}\text { Native } \\
\text { Speakers }\end{array}$ & $\begin{array}{c}\text { Non- } \\
\text { Native Sp* }\end{array}$ \\
\hline Build relationships with classmates & 2.5 & 1.6 & 2.5 & 1.0 \\
\hline Learn about your classmates & 2.0 & 1.8 & 2.3 & 1.0 \\
\hline Obtain useful information & 2.2 & 2.0 & 2.2 & 1.0 \\
\hline Obtain substantive advice & 2.7 & 2.4 & 2.7 & 3.0 \\
\hline Share ideas/experiences & 1.4 & 1.8 & 2.0 & 1.0 \\
\hline
\end{tabular}

* There was only one non-native student in SLA.

Students also felt that the discussion groups provided a locus of mutual support [cf. 10, 47]; by realizing that group members encountered similar learning or teaching experiences, students gained a new perspective on their own learning experience, which they may not otherwise have realized. In general, students found that the discussions offered them useful information and substantive advice, also observed by other researchers [14, 54]. Student comments, such as "getting other [classmates'] advice on a problem" and "getting advice from [my] classmates", illustrate this observation.

The assignment in this study also asked for students to remain in fixed groups throughout the semester. This was unlike other arrangements in the two classes, which typically assigned students to different groups in face-to-face class meetings with fair regularity. Thus, when group tasks were conducted in the classroom, students were usually assigned to different groups in each class session to collaborate on a task that would span the duration of one class only. However, unlike during their actual classroom time, 
students stayed in the same discussion board group for 12 weeks [cf. 18]. While students acknowledged the social benefits of such a long-term arrangement, the non-native students found the need to stay in unchanging groups less preferable (see Table 2), as one student's survey comment exemplifies: "Because I was [in a] group with non-native classmates. I'd like to be in a group of native speakers. I'd like to learn native writing style." Korenman and Wyatt point out that a group's "cohesiveness is fostered partly by the extent to which members know and like each other as individuals" [55], and group dynamics can also be influenced by students' age [54]. Thus, while in this study poor group dynamics did not affect each group's level of satisfaction with the web discussion assignment, the restricted opportunity to learn from native speakers was the most common concern for the non-native students in the Methodology class. As Table 2 shows, the non-native student in the SLA class, who was in a group with two native speakers, felt quite positive about remaining in the assigned group for the duration of the semester. This should be considered by instructors when assigning groups.

Table 2. Survey Results on Group Composition:

Averages for Native and Non-Native Students in the Two Classes.

\begin{tabular}{|c|c|c|c|c|}
\hline $\begin{array}{l}\text { Do you agree or disagree with the } \\
\text { following statements? }\end{array}$ & \multicolumn{2}{|c|}{ Methodology Class } & \multicolumn{2}{|c|}{$\begin{array}{c}\text { Second Language } \\
\text { Acquisition Class }\end{array}$} \\
\cline { 2 - 5 } Agree! 1-2-3-4-5 Disagree! & $\begin{array}{c}\text { Native } \\
\text { Speakers }\end{array}$ & $\begin{array}{c}\text { Non-Native } \\
\text { Speakers }\end{array}$ & $\begin{array}{c}\text { Native } \\
\text { Speakers }\end{array}$ & $\begin{array}{c}\text { Non- } \\
\text { Native Sp* }\end{array}$ \\
\hline I liked staying in the same group & 1.6 & 3.2 & 1.7 & 1.0 \\
\hline I would have liked to change groups & 4.1 & 2.8 & 4.1 & 4.0 \\
\hline
\end{tabular}

* There was only one non-native student in SLA.

\section{B. Students' Perceptions of Academic Benefits of Discussion Groups}

Collegial support appeared to provide an affective benefit for students by assuring them that they were not alone in not holding a clear understanding of course content [47]. Collegial support also provided a pedagogical benefit by identifying for students new strategies which they could use to gain an understanding of course content and by compelling students to keep up with course readings to be prepared for the group discussion. Both native and non-native students found that the asynchronous web discussions helped them understand course materials such as lectures, readings, and assignments [cf. 46] (see Table 3), and this was perceived as a slightly greater benefit by the non-native students. The groups provided an unthreatening forum in which non-native students could explore issues at their own pace, examine topics from various angles until they felt they had reached an understanding of material not presented in their native language [cf. 37]. Students pointed out that the asynchronous discussions within their groups helped them understand the class readings on a deeper level and provided clarification of various course-related issues. Student comments, such as "[I liked the] critical reflection on the readings" and "I could understand course readings on a deeper level", illustrate this [cf. 2, 3]. Typical in-class discussions often do not allow for topics to be discussed extensively since course syllabi tend to move from topic to topic in order to keep up with curricular goals, and this presents particular problems for nonnative speakers; in contrast, students were under no such pressure in their groups [cf. 20].

Table 3. Survey Results on Academic Benefits of Discussion Board Postings:

Averages for Native and Non-Native Students in the Two Classes.

\begin{tabular}{|l|c|c|}
\hline Did the electronic discussion help you ... & Methodology Class & $\begin{array}{c}\text { Second Language } \\
\text { Acquisition Class }\end{array}$ \\
\hline
\end{tabular}




\begin{tabular}{|l|c|c|c|c|}
\hline Very much 1-2-3-4-5 Not at all & $\begin{array}{c}\text { Native } \\
\text { Speakers }\end{array}$ & $\begin{array}{c}\text { Non-Native } \\
\text { Speakers }\end{array}$ & $\begin{array}{c}\text { Native } \\
\text { Speakers }\end{array}$ & $\begin{array}{c}\text { Non- } \\
\text { Native Sp* }\end{array}$ \\
\hline Understand course readings & 3.0 & 2.4 & 2.2 & 2.0 \\
\hline \multicolumn{1}{|c|}{ Understand course lectures } & 2.9 & 2.2 & 2.5 & 1.0 \\
\hline Understand course assignments & 2.8 & 1.8 & 2.9 & 1.0 \\
\hline Discuss ideas not raised in class & 1.5 & 2.0 & 2.2 & 1.0 \\
\hline Improve your writing skills & 3.7 & 2.8 & 3.3 & 3.0 \\
\hline
\end{tabular}

* There was only one non-native student in SLA.

In addition, students welcomed the opportunity to explore ideas that received little or no attention in class (see Table 3). This may be most relevant for the non-native speakers as they were often hesitant in contributing actively in a face-to-face classroom environment dominated by native English speakers [56]; and this was particularly obvious for the only non-native student in the SLA class, who was very quiet in face-to-face class meetings and group tasks, but made lengthy contributions (400+ words) to her group. Drake, Yuthas, and Dillard suggest that electronic discussions provide a forum for students hesitant to participate in the classroom in that students can "take more airtime than would be available in traditional [classroom] setting" [57] and thus bring up issues that are relevant to them, a finding echoed by students in a study by Wegerif [47].

Prior research had noted that regular discussion board postings can also help non-native students improve their writing skills in English [cf. 13]. However, students in the present study did not feel that their discussion board contributions contributed significantly to the development and improvement of these skills (see Table 3). While this is not surprising for native speakers, it is surprising for the non-native students, and echoes a similar finding by Stepp-Greany [42]. This indicates that students' primary focus in their discussion groups was on conveying meaning and content rather than on finessing syntactic constructions [58]. It is likely though that students' use of English improved over the course of the semester as a result of making regular postings. The joint development of ideas and arguments, the ongoing negotiation of meaning among group members may in fact have contributed to their development of academic language conventions as well as to the development of English for the non-native speakers in the classes $[12,13]$, but this would need to be investigated in a separate study.

\section{Students' Perceptions of Parameters of Discussion Board Postings}

While the students in the two classes agreed on the perceived advantages of the electronic discussion assignment for fostering positive relationships with their group members and enhancing understanding of course material, they did not embrace all aspects of the assignment. However, unlike in other studies of online student interactions where students felt their interactions were hampered by the lack of non-verbal clues typical of face-to-face interactions [for example, 22], students in the present study found themselves especially constrained by the requirement to respond to and build on previous group members' postings (see Table 4).

Table 4. Survey Results on Posting Requirements: Averages for Native and Non-Native Students in the Two Classes.

\begin{tabular}{|l|c|c|c|c|}
\hline \multicolumn{2}{|l|}{$\begin{array}{l}\text { Do you agree or disagree with the } \\
\text { following statements? }\end{array}$} & \multicolumn{2}{|c|}{ Methodology Class } & \multicolumn{2}{|c|}{$\begin{array}{c}\text { Second Language } \\
\text { Acquisition Class }\end{array}$} \\
\cline { 2 - 5 } Agree! $1-2-3-4-5 \quad$ Disagree! & $\begin{array}{c}\text { Native } \\
\text { Speakers }\end{array}$ & $\begin{array}{c}\text { Non-Native } \\
\text { Speakers }\end{array}$ & $\begin{array}{c}\text { Native } \\
\text { Speakers }\end{array}$ & $\begin{array}{c}\text { Non- } \\
\text { Native Sp* }\end{array}$ \\
\hline
\end{tabular}




\begin{tabular}{|l|c|c|c|c|}
\hline $\begin{array}{l}\text { The requirement to respond to previous } \\
\text { messages was too restrictive }\end{array}$ & 2.4 & 1.6 & 2.1 & 2.0 \\
\hline $\begin{array}{l}\text { The requirement to provide reflective } \\
\text { comments was clear }\end{array}$ & 2.6 & 2.4 & 2.6 & 2.0 \\
\hline
\end{tabular}

* There was only one non-native student in SLA.

Students' survey responses, especially those from the non-native students in the Methodology class, indicate that their motivation to add a new point to the ongoing exchange was hampered by the condition to forge an explicit link to a previous message. While it may be assumed that forging linguistic and semantic links to previous messages represents a challenge for non-native students who have to do this in a second language, the actual reason appeared to have little to do with lack of linguistic ability. For example, as one non-native student complained, "Should the discussion always be relevant to the previous one? I had a lot of topics that I wanted to talk [about]". Even though it was expected that the requirement to establish connections with previous messages would contribute positively to the dialogic and conversational nature of the electronic discussions [cf.13, 43], students perceived this as contributing to an artificiality of their exchanges with each other. Comments from native speakers, such as "not a real discussion", "restrictive", and "unnatural/inauthentic" illustrate this perception among the students, and the requirement to react to and expand on an existing topic may have stifled their enthusiasm to initiate a new topic or raise another point.

According to students' survey responses, the requirement for postings to include reflective thought was clear to them, as Table 4 indicates. However, even though the course instructor explained the expectations for reflective commentary, many students' postings - from native as well as non-native students - did not go beyond a retelling of course material in their own words and did not include the kind of reflection that showed critical evaluation and synthesis of information (a detailed discussion of students' postings is, h0wever, beyond the scope of this paper). This same lack of critical commentary in electronic discussions has also been observed by some other researchers [4] [23]. It is possible that students became too preoccupied with linking their postings to prior contributions, thus paying more attention to surface features, but it is also possible that a lack of "challenge and explain cycles" [22] considered a necessary ingredient in promoting critical reflection [54] curbed more reflective thought. It might also have been useful for the instructor to share sample postings with students that showed how students could add a more reflective dimension to their messages [4] without hurting their group members' feelings. Although students indicated when the assignment was introduced and indicated on the relevant survey question that the requirement to include reflective commentary was clear to them, some comments to the open-ended survey questions show that it in fact was not. Both native and non-native students responded: "What is reflective," "[What is the] meaning of "critical," and suggested that "more clarity on reflective comments" was needed. Thus, although students were given weekly feedback by the instructor, who would comment in writing on this aspect of the students' postings, students may have benefited from greater teacher presence during their group interactions [53] and from modeling sample postings, which could have aided them in including critical commentary in their postings [59].

In their survey responses, students also addressed the issue of the heavy extra workload - a "time burden" - not experienced through having to read through their group members' postings [cf. 47], but experienced through the addition of the weekly discussion board posting requirement. Similar findings are reported by other researchers as well $[42,46]$. None of the students felt that they had not posted enough throughout the semester, but native and non-native students were evenly divided with respect to deciding whether once-a-week postings were enough or too many, as the numerical results indicate (Table 5). Students' suggestions for improvements of the discussion board task show that they would have preferred more freedom in being able to select themselves when they wanted to contribute to their groups and in general 
suggested fewer postings per semester. This was perhaps because they "needed to balance [their] many [other] commitments" [46], as all students did have full-time or part-time work commitments.

Table 5. Evaluation of Posting Frequency.

\begin{tabular}{|l|c|c|c|c|}
\hline \multirow{2}{*}{$\begin{array}{l}\text { The requirement to post one message per } \\
\text { week was ... }\end{array}$} & \multicolumn{2}{|c|}{ Methodology Class } & \multicolumn{2}{c|}{$\begin{array}{c}\text { Second Language } \\
\text { Acquisition Class }\end{array}$} \\
\cline { 2 - 5 } & $\begin{array}{c}\text { Native } \\
\text { Speakers }\end{array}$ & $\begin{array}{c}\text { Non-Native } \\
\text { Speakers }\end{array}$ & $\begin{array}{c}\text { Native } \\
\text { Speakers }\end{array}$ & $\begin{array}{c}\text { Non- } \\
\text { Native Sp* }\end{array}$ \\
\hline$\ldots$ not enough & 0 & 0 & 0 & 0 \\
\hline$\ldots$ just enough & $3 / 17$ & $3 / 17$ & $10 / 19$ & $1 / 19$ \\
\hline$\ldots$ too much & $6 / 17$ & $2 / 17$ & $8 / 19$ & 0 \\
\hline & $\begin{array}{c}\text { Note that 3 students did not provide } \\
\text { responses. }\end{array}$ & \multicolumn{2}{|c|}{ All students responded. } \\
\hline
\end{tabular}

* There was only one non-native student in SLA.

Both native and non-native students also would have preferred assigned prompts to stimulate their web postings, as their responses to suggestions for modifying the discussion board task indicated. This would remove the burden of imposing a topic on the other group members, who may not be interested in a topic chosen by their classmate and also make the discussion less "unfocused" and "more structure[d]". Thus, even though it had been assumed that allowing students to select appropriate course-related discussion topics on their own would be perceived as a benefit to the assignment in allowing students to take on more responsibility for their own learning and increase motivation [32], the students in the two courses would have preferred more topic guidance, an observation also made by Beaudin [59]. Perhaps the newness of electronic postings to many students, as well as some students' comparison of the format in the present study to a teacher-initiated discussion format in the previous semester when BlackBoard was introduced at the university, may explain the students' preferences (see Table 6) [cf. 60]). As one nonnative student in the Methodology class commented: "Do this similar to [the] class last year."

Table 6. Prior Experience with Discussion Board Postings.

\begin{tabular}{|l|c|c|c|c|}
\hline \multirow{2}{*}{$\begin{array}{l}\text { Was this your first experience with } \\
\text { posting/ using a discussion board? }\end{array}$} & \multicolumn{2}{|c|}{ Methodology Class } & \multicolumn{2}{c|}{$\begin{array}{c}\text { Second Language } \\
\text { Acquisition Class }\end{array}$} \\
\cline { 2 - 5 } & $\begin{array}{c}\text { Native } \\
\text { Speakers }\end{array}$ & $\begin{array}{c}\text { Non-Native } \\
\text { Speakers }\end{array}$ & $\begin{array}{c}\text { Native } \\
\text { Speakers }\end{array}$ & $\begin{array}{c}\text { Non- } \\
\text { Native Sp* }\end{array}$ \\
\hline YES & $7 / 17$ & $3 / 17$ & $7 / 19$ & 0 \\
\hline NO & $3 / 17$ & $2 / 17$ & $10 / 19$ & $1 / 19$ \\
\hline & \multicolumn{2}{|c|}{$\begin{array}{c}\text { Note that 2 students did not provide } \\
\text { responses. }\end{array}$} & $\begin{array}{c}\text { Note that 1 student did not provide } \\
\text { response. }\end{array}$ \\
\hline
\end{tabular}

* There was only one non-native student in SLA.

The explicit weekly evaluation of students' postings by the instructor impacted the attitudes of most students in the two courses (see Table 7). Native speakers indicated that they became more concerned with "form and correct response" rather than "original thought". One native speaker in fact commented on having "used big words and confusing yet intellectual sentences" hoping to meet the criteria. Native speaker students also felt that the analytic criteria (see Appendix A) themselves were vague ("more detailed criterion"), thus dispelling the notion that rubrics always provide "unambiguous expectations" 
[2]. The native speakers felt that assessment was "arbitrary" and "picky" and would have preferred more constructive than evaluative feedback [14] and assessment on a "done/not done" basis, with the postings being entirely "optional". However, it is doubtful whether students would make any postings in the first place under such a format, and whether the postings would in fact be geared toward a learning purpose unless in fact they are structured and clearly integrated into other course components [4] [25] [41]. Interestingly, while the non-native students acknowledged that the teacher evaluation "made [them] sometimes less frank" and made them "nervous about writing itself", they - unlike the native speakers said they felt motivated by a good evaluation and did not make any comments about arbitrariness and pickiness of the instructor's assessment. This likely has cultural reasons; especially in Asian cultures, as was the background of most non-native students, in which students do not question teachers' assessment of their work.

Table 7. Effect of Instructor Evaluation of Postings.

\begin{tabular}{|l|c|c|c|c|}
\hline $\begin{array}{l}\text { Did the fact that your instructor evaluated } \\
\text { your messages affect your participation in } \\
\text { any way? }\end{array}$ & \multicolumn{2}{|c|}{ Methodology Class } & \multicolumn{2}{|c|}{$\begin{array}{c}\text { Second Language } \\
\text { Acquisition Class }\end{array}$} \\
\cline { 2 - 5 } & $\begin{array}{c}\text { Native } \\
\text { Speakers }\end{array}$ & $\begin{array}{c}\text { Non-Native } \\
\text { Speakers }\end{array}$ & $\begin{array}{c}\text { Native } \\
\text { Speakers } \\
\text { Native Sp* }\end{array}$ & $\begin{array}{c}\text { Non- } \\
\text { YES }\end{array}$ \\
\hline NO & $6 / 17$ & $4 / 17$ & $14 / 19$ & $1 / 19$ \\
\hline & $4 / 17$ & $1 / 17$ & $3 / 19$ & 0 \\
\hline
\end{tabular}

* There was only one non-native student in SLA.

When incorporating technology into their classes, instructors have to be aware that the technology is not infallible. Access to computer networks may break down, or the course web site is inaccessible due to upgrades or maintenance of the course management software, and instructors need to supply students with a back-up plan for such eventualities. Failure of technology to work as planned can affect students' perception of the usefulness of the task supported by the technology. As Table 8 shows, almost half the students in the present study said they experienced technological problems, but none of the students commented on this aspect as producing frustration or dissatisfaction. This is possibly because students indicated that their problems occurred only initially during the semester because they needed to become familiar with logging onto the BlackBoard system and access their particular groups' forum. Thus, once the process was a familiar one, students experienced no problems. When they could not log on to BlackBoard due to system maintenance or program failure, students could resort to the back-up procedures explained at the beginning of the semester. As a result then, students' negative perceptions of the discussion board task had little to do with technological problems but far more with the parameters of the task itself.

Table 8. Experience of Technological Problems during the Semester.

\begin{tabular}{|l|c|c|c|c|}
\hline $\begin{array}{l}\text { Did you experience any technological } \\
\text { problems? }\end{array}$ & \multicolumn{2}{|c|}{ Methodology Class } & \multicolumn{2}{|c|}{$\begin{array}{c}\text { Second Language } \\
\text { Acquisition Class }\end{array}$} \\
\cline { 2 - 5 } & $\begin{array}{c}\text { Native } \\
\text { Speakers }\end{array}$ & $\begin{array}{c}\text { Non-Native } \\
\text { Speakers }\end{array}$ & $\begin{array}{c}\text { Native } \\
\text { Speakers }\end{array}$ & $\begin{array}{c}\text { Non- } \\
\text { Native Sp* }\end{array}$ \\
\hline YES & $4 / 17$ & $4 / 17$ & $6 / 19$ & $1 / 19$ \\
\hline NO & $5 / 17$ & $1 / 17$ & $11 / 19$ & 0 \\
\hline
\end{tabular}




\begin{tabular}{|c|c|c|}
\hline & $\begin{array}{c}\text { Note that 3 students did not provide } \\
\text { responses. }\end{array}$ & $\begin{array}{c}\text { Note that 1 student did not provide } \\
\text { response. }\end{array}$ \\
\hline
\end{tabular}

* There was only one non-native student in SLA.

\section{DISCUSSION}

The use of collaborative computer technology—as well as any technology-needs to be employed deliberately to support students' learning, not simply because the technology is available. Too often technology is incorporated in classrooms with the vague rationale that technology will capture the attention of students and the expectation that subsequent positive affective effect itself will engage students in ways conducive to effective learning. However, the lure of new technology eventually wears thin and students may be left with more knowledge about the technology than about the substantive matters which were the actual focus of the course. Problematic in the present study was that university faculty were made aware of the ability of the course management software to extend out-of-class learning to a new medium but were not given sufficient support in determining how to integrate asynchronous discussions with their regularly meeting classes, especially when these classes have native and non-native participants. Therefore, it was critical that students provided feedback on their perceptions of the parameters of this discussion board task implemented that semester at the end of the school term.

Several aspects of the discussion board task were assessed generally positively by all students, namely social as well as academic benefits. The asynchronous nature of web board postings allowed the students to take time for deliberate reflection on the messages they were reading as well as posting without the pressures of synchronous interaction - either on-line or in the classroom [13, 16, 20, 29, 44, 52, 61, 62]. Thus, students could take the time to draft and revise their messages before submitting them to the group, which may have appealed particularly to those students with more reflective learning styles [10], those students who did not possess strong debating skills or outgoing personalities [47, 57], and those students who were not articulate in English [2], namely the non-native students in the two classes. The additional planning time as well as the encouragement to focus on content and ideas encouraged these students to take risks and bring up points related to course materials but not discussed in class, thus extending the application of relevant ideas to course content, as students noticed.

While classroom discussions tended to promote the participation of the more outgoing, vocal students (largely the native speakers), the electronic discussion groups provided an alternative forum in which all students could participate and contribute to the ongoing thread of topics [cf. 20]. While it was easier for non-native and less vocal students to remain silent in the physical classroom, the small size of the discussion groups as well as the parameters of the assignment in this study provided few reasons for students not to participate. Students felt more comfortable participating more fully in electronic discussions with a small but increasingly more familiar group of students $[1,2,12]$.

Chong [4] as well as Wegerif [47] discuss the development of online student communities as an advantage of discussion board collaborations. There is evidence that students in this study created their own online communities as well. Not only did they enjoy learning about each other, but over the course of the semester, each group also developed its own norms for interaction patterns, such the order of postings, length of postings, and how topics were related to readings and class discussions [cf. 55]. Since the instructor had not specified who would start a weekly posting cycle, how long postings should be, or what topic the group was to discuss, students had to develop their own mechanisms to address these aspects. During each weekly cycle, group members, especially native speakers, tended to linger in cyberspace waiting for someone to start the thread. This then led to last minute postings by all members, and thus made linking to the previous message by a group member more difficult as postings occurred nearly 
simultaneously. Non-native students appeared more conscientious in that a new posting cycle was started almost immediately after a face-to-face class meeting. Apparently, flexible time management skills often seen supported in asynchronous discussions [49] did not develop for all students in this study, especially not the native speakers, and reasons for why students delay postings should be examined in the future.

In the native speaker groups, it tended to be the same person who would initiate a weekly thread, followed in the same order each week by the other group members. Posting order in the groups with non-native students varied. Native speakers resourcefully worked out these technicalities within the electronic discussion itself while non-native students made efforts to arrange a posting sequence in class. If group members appeared not to keep up with their posting requirement, the native speakers did apparently not find this bothersome, unlike in a study conducted by Rossman [14]. Interestingly however, in the present study it was the non-native students who tended to complain to the instructor about group members who had not made postings by a certain date or in the expected order instead of solving the perceived problem within their group, online or offline. The high face threat of complaining to class members no doubt played a role in its avoidance.

Interestingly, the length of the postings within each group was in general fairly uniform, between 300 and 400 words, suggesting that students also developed an implicit standard as to what was considered an acceptable, sufficiently long posting as not one group addressed this issue explicitly in its electronic discussions. It was apparent that over time each group established its own rules as to the sequence and length of their postings. In one group in the Methodology class, one student consistently made postings exceeding 1,000 words, and it did not take long before the other two group members matched this length. In the SLA class, one group's postings did not exceed 300 words. Several students, notably native speakers, also noted in conversations with the instructor that they felt they needed to produce a high quality posting as they did not want their own contributions to be considered inferior to the group. Similar peer pressure toward higher quality postings have also been noted by other researchers [63] [64]. These aspects deserve greater scrutiny in a future study.

While the electronic discussions were generally useful in promoting social and academic benefits, several findings raise concerns about the use of the assignment in the current format.

The electronic discussions provided the students with a real audience and a realistic writing purpose; in other words, they required students to write for their peers, not only for the instructor. Therefore, in their groups, students had to do more than demonstrate knowledge; they also had to agree and disagree in unabrasive ways in a relatively public forum. It is the resolution of such areas of agreement and disagreement that "results in higher forms of reasoning" because "cognitive development requires that individuals encounter others who contradict their own intuitively derived ideas" [54]. However, disagreement in a public forum is difficult; Curtis and Lawson noted "absence of challenges to the input of others" in their study of asynchronous exchanges, which they attribute to lack of sufficient acquaintance among their students [22]. Similarly, the students in the present study avoided open "challenge and explain cycles" [22], as the following comment from a native speaker illustrates: "Sometimes I couldn't stand someone's opinion, but I couldn't complain or give opponent opinion because I had to stay in that group". A similar opinion is offered by a student in Wegerif's study: "it would seem rude to criticize [a group member's contribution] without commenting on it fully, and ... that would often take too long" [47]. Also, non-native speakers, particularly students from Asian countries, consider it far less appropriate to challenge and criticize ideas, and in addition, they may not know how to express disagreement appropriately in English. Electronic discussions could potentially provide an interesting preparation for the type of hedging often associated with academic writing if students in fact engage in it [cf. 14], but the visibility and permanence of postings as well as unfamiliarity among 
students who see each other only once a week during class time appear to present an obstacle to be overcome.

Students' neglect of making overt links to group members' messages may ironically have contributed to the "cumulative [rather than collaborative and interactive] style of knowledge construction" [47] that the students criticized in their survey responses. Thus, while in theory the ongoing linkage of a topic may provide a more in-depth discussion and look more like collaborative group learning by providing differing points of view [43], the requirement to provide such linkages in the form of first old, then new, information may run counter to what happens in authentic discussions. Whether or not one participant's point is picked up by a subsequent participant depends on how important a topic is to all participants [22], how much background knowledge participants have on the topic, and what new points they wish to raise. Moreover, for the non-native speakers in the courses, "poor control of discourse coherence" and "[in]ability to motivate [group members] to take part in the discussion [topic]" [13] may also account for the students' resistance to establishing topical connections.

Bannon points out that it may be difficult for students to achieve collaboration if they do not clearly perceive the goal of the activity [1, cf. also 18] - namely to help them deepen their perspectives on course content and foster learning. Similarly, Collins and Berge caution that computer-based student collaboration "may be perceived as an 'exercise' with high frustration levels unless students realize that the content of the discussions is a relevant part of the course" [10]. Students' survey responses indicate that the newness of the task may have been more confusing than motivating, and the instructor should have taken more time to inform students about the goals of the groups and postings and should perhaps have done so throughout the semester. Survey comments indeed indicate that students perceived the electronic discussions as "disconnected from everything else", failed to see the connection between the discussions and their own teaching and learning realities, and thus questioned "why it was supposed to be useful". Thus, instructors need to make an effort to clearly explain the rationale for the assignment at the outset of the semester [cf. 46] and to link issues brought up in the students' electronic discussions with issues brought up in face-to-face class meetings [cf. 59] - through instructor-posted weekly summaries of discussion points [cf. 14] or discussion of posting comments during class time. The instructor in the two courses did not address points students had initiated in the electronic discussions sufficiently in class, at least not from the students' perspective, as the student comments indicate.

Also, the absence of a specific task provided by the teacher may have lowered the sense of purpose [30]. Students suggested that the instructor provide prompts to discuss in the group, which may have heightened the sense of usefulness of the discussions for the students [cf. 59]. Chong's discussion of students" "tak[ing] ownership in the course" and "establish[ing] their subculture" [4] as advantages of electronic discussions might lead one to believe that students would have readily initiated discussions in this study. However, both native and non-native students indicated that they preferred to be given a topic to address [cf. 59]. This may be due to the newness of the assignment type and structure and perceived vagueness of instructor expectations on what would represent adequate topics, length, and reflection [2].

Chong had pointed out that the use of discussion boards to extend course-related discussions outside the classroom can become a burdensome form of busywork, and the majority of the students in this study reported that a once-a-week contribution to discussions was "too much" [4]. While once-a-week postings may seem a reasonable requirement for university courses, instructors of classes with non-traditional students who have full-time work commitments, family obligations, and other responsibilities may need to evaluate carefully how much time they can ask students to devote to out-of-class activities such as discussion board postings, especially if other assignments are not adjusted accordingly. Chong also points out that electronic discussions can provide students a forum in which students can "critique the course 
or...propose improvements in classroom teaching" [4]. This may, of course, depend on the students. None of the students in this study actually critiqued the electronic discussion exercise in their discussions although they did so in their responses to the survey at the end of the semester. This may not be surprising given the fact that the postings counted in their course grade.

Finally, although points were assigned for the assignment, these represented a fraction of the grade for participation, which in turn was only $10 \%$ of the final course grade. It may have been advisable to weight the discussion board postings comparably to the other activities and assignments in the two courses [cf. 4], especially since in the students' view they were expounding enormous effort on a weekly basis, unlike for other assignments that were given greater weight and occurred with less frequency. Increased weighting of the asynchronous discussion component would be a more adequate recognition of students' efforts [46], indicating the importance of this assignment, and may motivate students to take the activity more seriously than they might otherwise.

Instructors of graduate level courses who plan to incorporate asynchronous discussions into their courses to encourage students to reflect critically on course content should consider that - both native and nonnative speakers - students in the present study typically summarized course readings and related teaching and learning experiences only rather than analyzing, synthesizing, or evaluating them. This is unlike the laudatory findings of increased critical thinking skills claimed in other studies $[3,13,16,18,19,20,23$, 44]. Even though this was not the focus of the present study, this point deserves mentioning and needs to be examined more systematically in a future study. While little reflective thought may be the result of different definitions or expectations of critical thinking in different studies, or perhaps the result of the particular students in the two courses (a factor which could not be influenced by the instructor), it may also be the result of the particular format and structure of asynchronous discussions in this study. It is clear that asynchronous discussion outside the classroom will not automatically prompt or develop students' critical thinking $[18,23]$ or "create interaction and meaningful discussion" [4], as students' survey responses in the present study indicate. The present study suggests that the influence of the public nature of students' contributions to a discussion board needs to be considered when aiming to promote an intellectual give and take among students to develop critical thinking through discussion board forums.

Nevertheless, it has been observed that the ongoing, uninterrupted nature of electronic group discussions can contribute over time to critical thinking and complex reasoning skills $[3,18,19,20,44]$ as "coherent patterns of learning ... must accumulate over a series of [exchanges] and extracurricular experience" [51]. Asynchronous electronic discussions have the potential of promoting critical thinking precisely because students have more time to reflect on ideas before responding [cf. 16, 65] and because the discussions occur over the course of a semester. The discussions in this study do exhibit some evidence of critical thinking through application of ideas and concepts to new situations, through analysis and synthesis of multiple postings or readings, and through evaluation of theories, approaches, and claims. The following excerpts from two native speaker students in the Second Language Acquisition and Methodology course, respectively, illustrate this:

"It does sound like you learned hebrew [sic.] successfully in a classroom environment, but I would not rule out the effect of the indirect naturalistic setting on your language learning success. Although you might not have needed to use Hebrew outside of class, you were still bombarded with it. ... But there must have been road signs, newspapers, television programs all in hebrew [sic.] that were constantly in the background, not to mention all the conversations going on around you. ... These outside factors, in addition to your classroom learning, would have aided your success." 
"[W]hat could be more important to our success as ESL/EFL teachers than discovering the optimum theory-in-practice...Alas, such an animal is not to be found in Ellis - as you both point out, his "one the one hand, on the other hand" style effectively eliminates a firm adherence to any one magic bullet method. Actually I rather like his seemingly endless equivocation - maddening, yes, but ultimately it is more valuable than texts that dogmatically assert the superiority of this or that approach and ignore any contrary evidence that doesn't fall in line with its tenets. Surely it is preferable to know as much as it is possible to know about the pitfalls of every method."

Future research will need to inform instructors as to what specific parameters of discussion board tasks can elicit more critical thinking along these lines.

The ability to generalize findings beyond the present study is limited, due to the more descriptive, rather than statistical, nature of the data, but researchers' continued investigation of different applications and formats of asynchronous interaction in a variety of teaching and learning settings is necessary to advance our knowledge of how technology can best enhance students' learning. Instructors contemplating the use of asynchronous technology in graduate level university courses may benefit from the insights gained through this study. Future studies will need to investigate the parameters that determine when electronic discussions, and other interactive technologies, are effective learning tools [43, 48] and are perceived as such by the students for whom they are designed. There is a need for determining how course assignments integrating asynchronous technology in a specific course of study need to be prepared and structured throughout a semester in order to ensure that they are perceived as an integral component of the course and a valuable learning experience by the varied student populations at American universities [28, 35].

\section{APPENDIX A}

Electronic Group Journal Assignment: Student Instructions

1. Your instructor will assign you to a group of 3 or 4 students for the semester.

2. Within these groups, you will be expected to carry on electronic group discussions throughout the semester. That is, you will make weekly e-mail contributions meeting the following criteria:

- Contributions should be reflections of course content.

- These contributions need to include - but need not be limited to - evaluation of course content. In other words, they need to include critical reflection, not just description or summary.

- Each student is expected to send at least 1 message per week.

- Each message needs to be a reaction to previous messages. Contributions must build on previous contributions; that is, your contribution is not a separate, independent message without a relationship to messages from others in your group.

Your contributions will be rated against the above criteria. They will NOT be evaluated based on language accuracy. See the evaluation form below.

1. Send copies of all e-mail messages to all group members AND your instructor. 


\section{Weekly Evaluation Form for Electronic Group Journal Assignment}

Student:

Date:

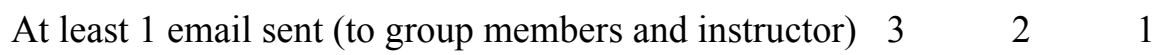

$\begin{array}{llll}\text { Messages are on course content } & 3 & 2 & 1\end{array}$

$\begin{array}{llll}\text { Messages include critical reflection } & 3 & 2 & 1\end{array}$

$\begin{array}{llll}\text { Messages build on previous messages } & 3 & 2 & 1\end{array}$

$3=$ Excellent, 2 = Satisfactory, $1=$ Needs improvement $\quad$ Points:

\section{APPENDIX B}

Native language:

Course:

\section{Electronic Discussion Group Survey}

1. Did the electronic discussion help you...? (Circle one number for each row.)

Very much

Not at all

Build relationships with classmates

Learn about your classmates

$\begin{array}{lllll}1 & 2 & 3 & 4 & 5 \\ 1 & 2 & 3 & 4 & 5\end{array}$

Understand course readings

$\begin{array}{llllll} & \mathbf{1} & \mathbf{2} & \mathbf{3} & \mathbf{4} & \mathbf{5} \\ 1 & 2 & 3 & 4 & 5 & \\ 1 & 2 & 3 & 4 & 5 & \end{array}$

Understand course assignments

Discuss ideas not raised in class

Obtain useful information

Obtain substantive advice

$\begin{array}{llllll} & \mathbf{1} & \mathbf{2} & \mathbf{3} & \mathbf{4} & \mathbf{5} \\ 1 & 2 & 3 & 4 & 5 & \\ 1 & 2 & 3 & 4 & 5 & \\ 1 & 2 & 3 & 4 & 5 & \\ 1 & 2 & 3 & 4 & 5 & \end{array}$

Improve your writing skills 
2. Do you agree or disagree with the following statements? (Circle one number for each row.)

The requirement to respond to previous

$$
\text { Agree! Disagree! }
$$

$\begin{array}{llllllll}\text { messages was too restrictive. } & 1 & 2 & 3 & 4 & 5\end{array}$

The requirement to provide reflective comments was clear.

I liked staying in the same group.

$\begin{array}{lllll}1 & 2 & 3 & 4 & 5\end{array}$

I would have liked to change groups.

$\begin{array}{lllll}1 & 2 & 3 & 4 & 5\end{array}$

$\begin{array}{lllllllll}\text { The amount of instructor feedback was appropriate. } & 1 & 2 & 3 & 4 & 5\end{array}$

3. Did you experience any technological problems? (Circle one.) Yes No How often? What kind?

4. One message per week was... (Check one.) _ not enough _ just enough _ too much How many messages would you have preferred to write (per week/month/semester)? per

5. Was this your first experience with posting/using a discussion board?

(Circle one.) Yes No

If not, what type of technology did you use in previous experiences?

_ Newsgroup __ Discussion Board __ Other:

6. If you would have liked to change groups, please explain why.

7. Was there anything not clear about the assignment? (If yes, please explain.) 
8. Did the fact that your instructor evaluated your messages affect your participation in any way?

(Circle one.) Yes No

How?

9. What was the greatest benefit of this assignment?

10. What was the greatest weakness of this assignment?

11. What suggestions would you give for modifying the assignment?

\section{ACKNOWLEDGEMENT}

I would like to thank Don Weasenforth for his helpful comments on an earlier draft of this paper. His interest in this research is greatly appreciated. I would also like to thank the $J A L N$ reviewers for their suggestions on an earlier version of this paper.

\section{REFERENCES}

1. Bannon, L., Issues in Computer Supported Collaborative Learning. In: O'Malley, C. (Ed.), Computer Supported Collaborative Learning. New York: Springer-Verlag, 267-281, 1995.

2. Rovai, A.A., A Preliminary Look at the Structural Differences of Higher Education Classroom, Communities in Traditional ALN Courses. Journal of Asynchronous Learning Networks, 6 (2): 41 56, 2002.

3. Campos, M., Laferriere, T., and Harasim, L., The Post-Secondary Networked Classroom: Renewal of Teaching Practices and Social Interaction. Journal of Asynchronous Learning Networks, 5 (2); 36-52, 2001.

4. Chong, S-M., Models of Asynchronous Computer Conferencing for Collaborative Learning in Large College Classes. In: Bonk, C. and King, K. (Eds.), Electronic Collaborators. Mahwah, NJ: Lawrence Erlbaum, 157-182, 1998.

5. Parker, D. and Gemino, A., Inside Online Learning: Conceptual and Technique Learning Performance in Place-Based and ALN Formats. Journal of Asynchronous Learning Networks 5 (2): 64-74, 2001.

6. Bonk, C. J. and King, K. (Eds.), Electronic Collaborators: Learner-Centered Technologies for Literacy, Apprenticeship, and Discourse. Mahwah, NJ: Lawrence Erlbaum, 1998.

7. Crook, C., Computers and the Collaborative Experience of Learning. New York: Routledge, 1994.

8. Joy, E.H. and Garcia, F.E., Measuring Learning Effectiveness: A New Look at No- SignificantDifference Findings. Journal of Asynchronous Learning Networks, 4 (1); 33-39, 2000. http://www.sloan-c.org/publications/jaln/v4n1/v4n1 joygarcia.asp

9. Buzzard, J., MacLeod, L., and DeWitt, C.W., Enhancing Student Learning Through Electronic Communication, 1997. http://www.mtsu.edu/ itconf/proceed97/buzzard.html

10. Collins, M. and Berge, Z., Facilitating Interaction in Computer Mediated Online Courses. Paper presented at the FSU/AECT Distance Education Conference. Tallahassee, FL, June 1996. 
11. Higher Education Research Institute, An Overview of the 1998-99 Faculty Norms. UCLA Graduate School of Education and Information Studies, 1999. http://www.gseis.ucla.edu/heri/fac po.html .

12. Kahmi-Stein, L., Looking to the Future of TESOL Teacher Education: Web-Based Bulletin Board Discussions in a Methods Course. TESOL Quarterly, 34 (3): 423-455, 2000.

13. Lamy, M-N. and Goodfellow, R., Reflective Conversation in the Virtual Classroom. Language Learning \& Technology 2 (2): 43-61, 1999.

14. Rossman, M.H., Successful Online Teaching Using an Asynchronous Learner Discussion Forum. Journal of Asynchronous Learning Networks, 3 (2): 1-8, 1999. http://www.sloan-c.org/publications/jaln/v3n2/v3n2_rossman.asp

15. Wegner, S.B., Holloway, K.C., and Garton, E.M., The Effects of Internet Based Instruction on Student Learning. Journal of Asynchronous Learning Networks, 3 (2): 98-106, 1999. http://www.sloan-c.org/publications/jaln/v3n2/v3n2 wegner.asp

16. Aviv, R., Educational Performance of ALN Via Content Analysis. Journal of Asynchronous Learning Networks, 4 (2), 2000. http://www.sloan-c.org/publications/jaln/v4n2/v4n2 aviv.asp

17. Jonassen, D.H., Technology as Cognitive Tools: Learners as Designers. IT Forum Paper \#1, 1994. http://it.coe.uga.edu/itforum/paper1/paper1.html .

18. Scarce, R., Using Electronic Mail Discussion Groups to Enhance Students' Critical Thinking Skills, July 1997. http://ts.mivu.org/default.asp?show + article\&id=526 .

19. Shapley, P., On-Line Education to Develop Complex Reasoning Skills on Organic Chemistry. Journal of Asynchronous Learning Networks, 4 (2), 2000.

20. Weasenforth, D., Meloni, C., and Biesenbach-Lucas, S., Impact of Asynchronous Electronic Discussions on Native and Non-Native Students' Critical Thinking. In Proceedings of Learning on Line 2000: Reassessing the Virtual University. Roanoke, VA: Virginia Tech, 2000. http://www2.cddc.vt.edu/lol2/papers/Beisenbach.pdf.

21. Bennett, L. and Pye, J., Technology: Creating a Community of Thinkers. In: Proceedings of Selected Research and Development Presentations at the $20^{\text {th }}$ National Convention of the Association for Educational Communications and Technology (AECT), 1999.

22. Curtis, D.D. and Lawson, M.J., Exploring Collaborative Online Learning. Journal of Asynchronous Learning Networks, 5 (1): 21-34, 2001. http://www.sloan-c.org/publications/jaln/v5n1/v5n1 curtis.asp

23. Hettinger, G., Raising the Level of the Debate: The Effects of Computer-Mediated Communication on Group Dynamics and Critical Thinking Skills. In: Proceedings of the 1995 Annual National Convention of the Association for Educational Communications and Technology (AECT), Anaheim, CA, 1995.

24. Kelly, J., Effective Reflection: Using Computer Conferencing as the Writing Component of a Service Learning Course. Paper presented at The $48^{\text {th }}$ Annual Meeting of the Conference on College Composition and Communication. Phoenix, AZ, 1997.

25. MacKinlay, K., Planning to Use Email to Support the Learning Process? 1999. http://www.edfac.unimelb.edu.au/online-ed/mailouts/1999/Sept6.html

26. O'Brien, S.R., The Medium Facilitates the Messages: Electronic Discourse and Literature Class Dynamics. Computers and Composition, 11 (1): 79-86, 1994.

27. Walther, J.B., Anticipated Ongoing Interaction Versus Channel Effects on Relational Communication in Computer-Mediated Interaction. Human Communication Research, 20 (4): 473501, 1994.

28. Weasenforth, D., Biesenbach-Lucas, S, and Meloni, C., Realizing Constructivist Objectives Through Collaborative Technologies: Threaded Discussions. Language Learning \& Technology, Special Issue, 6 (3): 58-86, 2002.

29. Tait, A., Face-to-Face and at a Distance: The Mediation of Guidance and Counseling Through the New Technologies. British Journal of Guidance and Counseling, 27 (1): 113-122, 1999. 
30. Johnson, D.W. and Johnson, R.T., Cooperation and the Use of Technology. In: Jonassen, D.H. (Ed.), Handbook of Research for Educational Communications and Technology, New York: Simon \& Schuster, 1017-1044, 1996.

31. Kirkley, S. E., Savery, J. R., and Grabner-Hagen, M. M., Electronic Teaching: Extending Classroom Dialogue and Assistance Through E-Mail Communication. In Bonk, C. and King, K. (Eds.), Electronic Collaborators, Mahwah, NJ: Lawrence Erlbaum, 209-232, 1998.

32. Weasenforth, D., Meloni, C., and Biesenbach-Lucas, S., Learner Autonomy and Course Management Software. In: Shelley, M. (Ed.), [title to be determined]. Multilingual Matters, forthcoming 2003.

33. Nunan, D., Second Language Teaching and Learning. Boston: Heinle and Heinle, 1999.

34. Grabe, M. and Grabe C., Integrating Technology for Meaningful Learning. New York: Houghton Mifflin, 1998.

35. Biesenbach-Lucas, S., Asynchronous Web Discussions in Teacher Training Courses: Promoting Collaborative Learning - or Not? Educational Technology Review, forthcoming 2003.

36. Warschauer, M., Computer-Mediated Collaborative Learning: Theory and Practice. Research Note \#17. Honolulu: University of Hawai'i, Second Language Teaching \& Curriculum Center, 1996.

37. O’Malley, C., Designing Computer Support for Collaborative Learning. In: O’Malley, C. (Ed.), Computer Supported Collaborative Learning. New York: Springer-Verlag, 283-297, 1995.

38. Scheurman, G., Using Principles of Constructivism to Promote Reflective Judgment: A Model Lesson. Journal on Excellence in College Teaching, 8 (2): 63-86, 1997.

39. Berge, Z., Changing Roles of Teachers and Learners Are Transforming the Online Classroom, 1998. http://www.edfac.unimelb.edu.au/online-ed/mailouts/1998/aug30.html.

40. Benbunan-Fich, R. and Hiltz, S.R., Impacts of Asynchronous Learning Networks on Individual and Group Problem Solving: A Field Experiment. Group Decision and Negotiation, 8: 409-426, 1999.

41. Harasim, L., Collaborating in Cyberspace: Using Computer Conferences as a Group Learning Environment. Interactive Learning Environments, 3: 119-130, 1993.

42. Stepp-Greany, J., Student Perceptions on Language Learning in a Technological Environment: Implications for the New Millennium. Language Learning and Technology, 6 (1): 165-180, 2002.

43. Hiltz, S.R., Coppola, N., Rotter, N., Turoff, M., and Benbunan-Fich, R., Measuring the Importance of Collaborative Learning for the Effectiveness of ALN: A Multi-Measure, MultiMethod Approach. Journal of Asynchronous Learning Networks, 4 (2), 2000.

http://www.sloan-c.org/publications/jaln/v4n2/v4n2 hiltz.asp

44. Greenlaw, S.A. \& DeLoach, S.B., Teaching Critical Thinking with Electronic Discussion. Journal of Economic Education, forthcoming 2003.

45. Müller-Hartmann, A., The Role of Tasks in Promoting Intercultural Learning in Electronic Learning Networks. Language Learning and Technology, 4 (2): 129-147, 2000.

46. Graham, M., Scarborough, H., and Goodwin, C., Implementing Computer-Mediated Communication in an Undergraduate Course - A Practical Experience. Journal of Asynchronous Learning Networks, 3 (1): 1-15, 1999.

47. Wegerif, R., The Social Dimension of Asynchronous Learning Networks. Journal of Asynchronous Learning Networks, 2 (1): 34-49, 1998. http://www.sloan-c.org/publications/jaln/v2n1/v2n1_wegerif.asp

48. Picciano, A.G., Beyond Student Perceptions: Issues of Interaction, Presence, and Performance in an Online Course. Journal of Asynchronous Learning Networks, 6 (1): 21-40, 2002. http://www.sloan-c.org/publications/jaln/v6n1/v6n1_picciano.asp

49. Valenta, A., Therriault, D., Dieter, M., and Mrtek, R., Identifying Student Attitudes and Learning Styles in Distance Education. Journal of Asynchronous Learning Networks, 5 (2), 111127, 2001. http://www.sloan-c.org/publications/jaln/v5n2/v5n2_valenta.asp

50. Polichar, V.E. and Bagwell, C., Pedagogical Principles of Learning in the Online Environment. Syllabus, 52-56, May, 2000. 
51. Ehrmann, S.C., Asking the Right Question: What Does Research Tell Us About Technology? and Higher Learning? 1997. http://www.learner.org/edtech/rscheval/rightquestion.html.

52. Sotillo, S.M., Discourse Functions and Syntactic Complexity in Synchronous and Asynchronous Communication. Language Learning \& Technology, 4 (1): 82-119, 1999.

53. Anderson, T., Rourke, L., Garrison, D.R., and Archer, W., Assessing Teacher Presence in a Computer Conferencing Context. Journal of Asynchronous Learning Networks, 5 (2): 1-17, 2001.

54. Shaw, G.P. and Pieter, W., The Use of Asynchronous Learning Networks in Nutrition Education: Student Attitude, Experiences and Performance. Journal of Asynchronous Learning Networks, 4 (1): 40-51, 2000. http://www.sloan-c.org/publications/jaln/v4n1/v4n1 shawpieter.asp

55. Korenman, J. and Wyatt, N., Group Dynamics in an E-Mail Forum. In: Herring, S. (Ed.), Computer-Mediated Communication: Linguistic, Social, and Cross-Cultural Perspectives. Amsterdam: John Benjamins, 225-242, 1996.

56. Morrison, J.L., The Computer Conference: Adaptive Problem Solving within a Spontaneous Technological Framework. Educational Technology, 46-47, December 1992.

57. Drake, B., Yuthas, K., and Dillard, J.F., It's Only Words - Impacts of Information Technology on Moral Dialogue. JBE, 23 (1): 41-59, 2000.

58. Sanaoui, R. and Lapkin, S. A Case Study of an FSL Senior Secondary Course Integrating Computer Networking. The Canadian Modern Language Review, 43 (3): 524-552, 1992.

59. Beaudin, B.P., Keeping Online Asynchronous Discussion on Topic. Journal of Asynchronous Learning Networks, 3 (2): 41-53, 1999. http://www.sloan-c.org/publications/jaln/v3n2/v3n2 beaudin.asp

60. Wang, X.C., Kanfer, A., Hinn, D.M., and Arvan, L., Stretching the Boundaries: Using ALN to Reach On-Campus Students During an Off-Campus Summer Session. Journal of Asynchronous Learning Networks, 5 (1): 1-20, 2001. http://www.sloan-c.org/publications/jaln/v5n1/v5n1_arvan.asp

61. Ocker, R.J. and Yaverbaum, G.J., Asynchronous Computer-Mediated Communication Versus Face-to-Face Collaboration: Results on Student Learning, Quality, and Satisfaction. Group Decision and Negotiation, 8: 427-440, 1999.

62. Aiken, M.W., Advantages of Group Decision Support Systems. Interpersonal Computing \& Technology, 1 (3), 1993. http://www.helsinki.fi/science/optek/1993/n3/aiken.txt .

63. Barreau, D., Eslinger, D., McGoff, K., and Tonnesen, C., Group Collaboration in the Virtual Classroom: An Evaluation of Collaborative Learning in the Virtual Classroom of CMSC 828S and the Technology That Supports It. Journal of Virtual Experience, 1993. http://www.hitl.washington.edu/research/knowledge base/virtual-worlds/JOVE/index.html.

64. Hiltz, S.R., Impacts of College-Level Courses Via Asynchronous Learning Networks: Some Preliminary Results. Journal of Asynchronous Learning Networks, 1 (2); 1-19, 1997. http://www.sloan-c.org/publications/jaln/v1n2/v1n2 hiltz.asp

65. Bedell, J., Moore, M., and Sorensen-Nunez, G., Students' Views of Their Learning: Bloom's Taxonomy, and the Computer. Technology for Learning: Instructional Issues in ANER., Fullerton, CA: California State University, 1999.

\section{ABOUT THE AUTHOR}

Sigrun Biesenbach-Lucas is Assistant Professor in the TESOL Program at American University where she teaches graduate level courses in ESL/EFL methodology, second language acquisition, and TESOL research. Her research centers on two major focal interests: cross-cultural pragmatics, i.e. analysis of request realizations of native and non-native students in email interactions with faculty in graduate level courses, and the effect of technology on student perceptions and education, i.e. how asynchronous technology can best be used to support learning in her teacher training own courses, in which native and non-native students are enrolled. 